\title{
ROAD TRAFFIC ACCIDENTS IN BANGLADESH
}

Road traffic injuries remain a major cause of death, injury and disability all over the world. The Global Status Report on Road Safety states that over 1.2 million people die each year on the world's roads. A much larger number (between 20 and 50 million) suffer non-fatal injuries. Few countries have reliable data on road traffic injuries out of which Bangladesh is one. Reliable data on deaths and non-fatal injuries are needed by countries to assess the scope of their road traffic injury problem, to target responses to it, and to monitor and evaluate the effectiveness of intervention measures. Underreporting of road traffic deaths remain a big problem in many countries, and the situation is even worse with regard to non-fatal injuries.

Road safety action requires the involvement of many different disciplines and the cooperation of a wide range of government, private and civil sectors with a firm governmental/organizational commitment. Recognition of the seriousness of the road accident problem by the Government of Bangladesh is reflected in the various measures taken to combat the alarming situation. The National Road Safety Council (NRSC) was established in 1995, which drew up the National Road Safety "Strategic Action Plan" covering the period from July 1997 to June 1999. Subsequently, a revised three-year action plan (2002-2004) was prepared in November 2001. Currently there are two core organizations responsible for preparing the national policy on road safety and ensuring its implementation. These are the National Road Safety Council (NRSC) and the Road Safety Cell (RSC). The NRSC acts as the apex body for approving and driving forward the national policy and plans, whereas the RSC established at the Bangladesh Road Transport Authority (BRTA) carries out preparation of plans, coordination, and monitoring and evaluation of planned activities assigned to different agencies and implementation of some programmes assigned to it.

Besides NRSC, The Road Safety Action Plan identified nine priority sector activities for improvement. These are: Planning, management and coordination; Accident data system; Road engineering;
Traffic legislation; Traffic enforcement; Driver training and testing; Vehicle safety; Education and publicity; and Medical services. Indeed, the focus activities of the strategic action plan are similar to those covered by the ADB/ESCAP road safety guidelines (ADB, 1997). For the purpose of implementation of the road safety action plan, the following leading agents have been nominated. These are: Roads and Highways Department (RHD); Dhaka City Corporation (DCC); Bangladesh Police; Bangladesh Road Transport Authority (BRTA); Ministry of Education and the Ministry of Health. But till date, very little has been done or achieved in relation to road safety. According to the official statistics, in 2000 there were about 4000 fatalities from Road Traffic Accident alone. In an estimate made by the Police HQ in 2000, there were 3970 no. of accidents causing 4046 no. of fatalities estimating 2270 no. of injuries and 163 deaths per 10000 vehicles.

Between $70-80 \%$ of RTAs occur on highways and rural roads. Up to $70 \%$ of road accidents are pedestrians alone. Trucks and buses are major contributors to road traffic accident fatalities. From a hospital based study, it has been found that injury patients comprised more than one fifth of all admissions and about half (49.8\%) of all surgical beds of a district hospital. At the first referral level, graduate physicians are providing trauma care. In every teaching hospital, there is a full fledged department of Orthopaedic surgery, where trauma patients are managed by trained physicians. At national level, there is a National Institute for Traumatology and Rehabilitation providing specialized services to trauma victims. Besides government health facilities a number of NGO and private clinics are also providing trauma care services to injury victims. Besides all these facilities, five trauma centers have been established by the side of some high risk national highways to provide emergency services to trauma victims.

Too many accidents are still occurring needlessly and taking the lives of innocent people, mainly through the reckless behaviour of the drivers of buses and trucks. 
Vehicles pass fitness tests without proper verification. Obtaining driving licenses are either too easy or too difficult and motor driving schools remain unsupervised and have not been given any scope to get involved in the development of the traffic safety programme. We strongly urge government and private agencies involved in roads and traffic as well as the road using public to do everything possible to address this problem which has become a public health issue of gigantic proportions in our country.

Prof. Mamunar Rashid

Professor \& Head

Department of Community Medicine

Ibrahim Medical College 